\title{
Effects of Titania-Silicon Carbide Additives on The Phase Development and Properties of Sintered Mullite-Carbon Composite
}

\author{
Aramide Fatai O. and Popoola Patricia A
}

\author{
Department of Chemical, Metallurgical and Materials Engineering, Tshwane University of \\ Technology, Staatsartillerie Road, Pretoria West, South Africa
}

\begin{abstract}
The effects of the additives (silicon carbide and titania) and sintering temperatures on the phases developed, physical and mechanical properties of sintered mullite-carbon ceramic composite produced from kaolin and graphite was investigated. The kaolin and graphite of known mineralogical composition were thoroughly blended with 5 and 3 (vol.) \% silicon carbide and titania respectively. From the homogeneous mixture of kaolin, graphite and titania, standard samples were prepared via uniaxial compaction. The test samples produced were subjected to firing (sintering) at $1300^{\circ} \mathrm{C}, 1400^{\circ} \mathrm{C}$ and $1500^{\circ} \mathrm{C}$. The sintered samples were characterized for the developed phases using x-ray diffractometry analysis, microstructural morphology using ultrahigh resolution field emission scanning electron microscope (UHRFEGSEM). Various physical and mechanical properties were determined. It was observed that the addition of $\mathrm{SiC} / \mathrm{TiO}_{2}$ additives to the samples made them to possess very low oxidation indices .This also resulted in improvement in the bulk densities and cold crushing strength of the sample when compared with those without additives. It was concluded that the addition of $\mathrm{SiC} / \mathrm{TiO}_{2}$ additives improves on the high temperature oxidation resistance of the mullite-carbon ceramic composite sample.
\end{abstract}

Keywords: titania; kaolin; carbon; sintering temperatures; phases developed; sintered ceramic composite

\section{Introduction}

Ceramic materials, which are mostly refractory, are vital for the technological developments being observed today $[1,2]$. Imagine how possible it would have being to handle molten metal/alloys before casting into desired components. But the major setback for ceramic materials is their brittleness. This is why the development of refractory ceramic composites to improve on their properties is very important. It has been stated that if monolithic ceramics (unreinforced) is subjected to about $0.1 \%$ tensile strain, it will fail catastrophically. But when reinforced with fibers, it could withstand more than $0.5 \%$ tensile strain [3-5].

Many researchers have reported their findings on the various work they carried out on ceramic composites. Das and Banerjee, (2000) [6] produced zirconia-mullite composites through solidstate reaction sintering of zircon flour, alumina and dysprosia as sintering additive. Some other researchers [7] employed different processing routes for production of zirconia-mullite composites, which are reaction sintering of alumina and zircon and direct sintering of mullitezirconia grains by slip casting and sintered at $1600^{\circ} \mathrm{C}$ for 2 hours. Another group [8] used acicular aluminum borate templates to nucleate textured mullite-zirconia composites prepared from a reactive mixture of alumina and zircon powders. Badiee et al. (2001) [9] investigated the effects of $\mathrm{CaO}, \mathrm{MgO}, \mathrm{TiO}_{2}$, and $\mathrm{ZrO}_{2}$ on mullitization of the Iranian andalusite located. They discovered that only zirconia did not encouraged mullite formation from andalusite. Ebadzadeh and Ghasemi 
(2002) [10] prepared zirconia-mullite composites using $\alpha$-alumina and aluminium nitrate and zircon powder with $\mathrm{TiO}_{2}$ as additive. Aramide et al. (2014) [11] synthesized mullite-zirconia composites containing yttria as additive. Chandra et al. (2013) [12] prepared zirconia-toughened ceramics with a mullite matrix based on the quaternary system $\mathrm{ZrO}_{2}-\mathrm{Al}_{2} \mathrm{O}_{3}-\mathrm{SiO}_{2}-\mathrm{TiO}_{2}$ in the temperature range $1450-1550^{\circ} \mathrm{C}$ using zircon-alumina-titania mixtures. Aksel and Komicezny (2001) [13] studied the influence of zircon on the mechanical properties and thermal shock behavior of slip-cast alumina-mullite refractories.

The presence of various additives in the ceramic composite bodies has a lot of influence on the various properties of the ceramic material. Some of these additives aid the formation of the reinforcing component. Different authors have demonstrated that mullitization can be increased by catalytic ions such as $\mathrm{Fe}^{3+}$ and $\mathrm{Ti}^{4+}[14,15]$. These metallic ions help in mullite formation by replacing the $\mathrm{Al}^{3+}$ ions in the glass structure during firing. The presence of small amounts of $\mathrm{Fe}^{3+}$ and $\mathrm{Ti}^{4+}$ in kaolin modifies the chemical composition of the ceramic bodies and therefore the sintering behavior which in the case of porcelain is characterized by mullitization. Aramide et al. (2016) [16] had synthesized mullite-carbon composite from the same materials without any additive. The objective of the present work is to improve the properties of the mullite-carbon ceramic composite through the use of combined titania and silicon carbide.

\section{Materials and Methods}

\subsection{Raw Materials}

Clay sample used for this study (as mine Kaolin sample) was sourced from Okpella, Edo State southern part of Nigeria, Graphite and titania $\left(\mathrm{TiO}_{2}\right)$ were sourced from (Pascal Chemicals, Akure), this were used to maintain the granulometry of the mixture.

\subsection{Method}

\subsubsection{Processing of raw materials (Graphite and Kaolin)}

The raw materials (graphite and kaolin) were crushed into a coarse particle size, of about $10 \mathrm{~mm}$ for graphite and less than $2 \mathrm{~mm}$ for kaolin; the crushed samples were further reduced by grinding using Herzog rod mill. The powdered samples were sieved using $600 \mu \mathrm{m}$ sizes aperture according to ASTM standards in an electric sieve shaker. The undersize that passed through the $600 \mu \mathrm{m}$ sieve aperture were used in the samples making.

\subsubsection{Phase and Mineralogical Composition of Raw kaolin and Graphite}

The kaolin clay and graphite samples were carefully prepared for these analyses by digesting in reagents as described by Nabil and Barbara, (2012) [17]. The mineralogical phases present in the samples were determined using X-ray diffractometry (XRD).

\subsection{Experimental Procedure}

\subsubsection{Composition calculation using the Rule of Mixtures Technique}


The mass percent of the above compositions were individually calculated using Equations (1) and (2) using the density and the individual powders volume fraction in each composition. The powders were weighed per batch of $50.00 \mathrm{~g}$ on a sensitive electronic weighing balance to five (5) decimal places [11]. The individual (batch) composition was thoroughly mixed in a Turbula Mixer for 18 hours at a speed of $72 \mathrm{rev} / \mathrm{min}$. If

$$
M_{t}=V_{k} \rho_{k}+V_{\mathrm{SiC}} \rho_{\mathrm{SiC}}+V_{\mathrm{TiO}_{2}} \rho_{\mathrm{TiO}_{2}}
$$

where $\mathrm{V}_{\mathrm{k}}, \mathrm{V}_{\mathrm{SiC}}$ and $\mathrm{V}_{\mathrm{TiO} 2}$ are respectively the volume fraction of kaolin, $\mathrm{SiC}$ and $\mathrm{TiO}_{2}, \rho_{\mathrm{k}}, \rho_{\mathrm{SiC}}$ and $\rho_{\mathrm{TiO} 2}$ are respectively the density of kaolin, $\mathrm{SiC}$ and $\mathrm{TiO}_{2} . \mathrm{M}_{\mathrm{t}}$ is the total mass contribution of all the components. And if $\mathrm{M}$ is the mass of each batch, then the mass contribution of each component could be calculated from:

$$
\mathrm{Mc}=\frac{\mathrm{V} c \rho \mathrm{c} \times \mathrm{M}}{\mathrm{Mt}}
$$

$\mathrm{Mc}$ is the mass contribution of a component in a batch ( $\mathrm{kaolin}$ or $\left.\mathrm{SiC}_{\mathrm{C}} \mathrm{TiO}_{2}\right), \mathrm{Vc}, \rho_{\mathrm{c}}$ the respective volume fraction and density of the component.

The resulting homogenous powder mixtures were compacted uniaxially into standard sample dimensions for the various analyses.

\subsubsection{Composites Production}

The raw materials in the samples making were 3:2vol. \% of kaolin and graphite respectively with the addition of 5 and 3 (vol.) \% silicon carbide and titania respectively. The mixture were blended thoroughly for proper distribution of constituents materials in a ball mill for 3 hours at a speed of $72 \mathrm{rev} / \mathrm{min}$ after weighing via electronic weighing balance in accordance with the composition calculation initially prepared $[11,18]$. The resulting blended compositions were mixed with $10 \%$ water, the amount of kaolin content in each composition, this was in order to enhance the plasticity of the mixture during compaction. The mixed samples were subjected to uniaxial compaction, which was carried out mechanically under pressure. The moulded materials were fired at varying temperatures $\left(1300^{\circ} \mathrm{C}, 1400^{\circ} \mathrm{C}\right.$ and $\left.1500^{\circ} \mathrm{C}\right)$. After which the samples were subjected to various test, to examine the phase analysis, evaluate their physical and mechanical properties.

\subsection{Testing}

\subsubsection{Shrinkage Measurement}

The shrinkage properties of the pressed samples were determined by measuring both the green and fired dimensions, using a digital vernier caliper. The thickness and diameters were measured for evaluation and computation of the shrinkage [18].

$$
\% \text { linear shrinkage }=\frac{(L g-L f)}{(\mathrm{Lg})} \times 100
$$

where: $L g$ represent the green length and Lf represent the fired length.

$$
\% \text { volumetric shrinkage }=\frac{(V g-V f)}{(\mathrm{Vg})} \times 100
$$

where Vg represent the green volume and Vf represent the fired Volume

\subsubsection{Apparent porosity}


Test samples from each of the ceramic composite samples were dried out for 12 hours at $110^{\circ} \mathrm{C}$. The dry weight of each fired sample was taken and recorded as D. Each sample was immersed in water for 6 hours to soak and weighed while being suspended in air. The weight was recorded as W. Finally, the specimen was weighed when immersed in water $[11,18]$. This was recorded as S. The apparent porosity was then calculated from the expression:

\subsubsection{Bulk Density}

$$
\% \text { apparent porosity }=\frac{(W-D)}{(\mathrm{W}-\mathrm{S})} \times 100
$$

The test specimens were dried out at $110^{\circ} \mathrm{C}$ for 12 hours to ensure total water loss. Their dry weights were measured and recorded. They were allowed to cool and then immersed in a beaker of water. Bubbles were observed as the pores in the specimens were filled with water. Their soaked weights were measured and recorded. They were then suspended in a beaker one after the other using a sling and their respective suspended weights were measured and recorded $[11,18]$. Bulk densities of the samples were calculated using the formula below:

$$
\text { Bulk density }=\frac{D}{(\mathrm{~W}-\mathrm{S})}
$$

where D represents weight of dried specimen, S represents weight of dried specimen suspended in water, and $\mathrm{W}$ represents weight of soaked specimen suspended in air.

\subsubsection{Cold Compression Strength, Modulus of Elasticity and Absorbed Energy}

Cold compression strength test is to determine the compression strength to failure of each sample, an indication of its probable performance under load. The standard ceramic samples were dried in an oven at a temperature of $110^{\circ} \mathrm{C}$, allowed to cool. The cold compression strength tests were performed on INSTRON 1195 at a fixed crosshead speed of $10 \mathrm{~mm} \mathrm{~min}^{-1}$. Samples were prepared according to ASTM C133-97 (ASTM C133-97, 2003) [11, 18] cold crushing strength, modulus of elasticity and absorbed energy of standard and conditioned samples were calculated from the equation:

$$
\text { Cold Crushing Strength }=\frac{(\text { Load to fracture })}{(\text { Surface area of sample })}
$$

\subsubsection{Oxidation Resistance}

The fired samples after heat-treatment were cut and the diameter of black portion was measured at different locations and the average value was taken. Lower oxidation index indicates the higher oxidation resistance of the sample [19, 20]. Oxidation index is determined by the formula:

$$
\text { Oxidation index }=\frac{\text { Area of oxidized zone }}{\text { Total area }} \times 100
$$

\section{Results and Discussion}

\subsection{Effects of Sintering Temperature on the Phase Development, Mechanical and Properties of Mullite-Carbon Ceramic Composite Samples}




\subsubsection{Effects of Sintering Temperature on the Phase Development in the Mullite-Carbon Ceramic Composite Samples}

The XRD pattern for the sintered ceramic composite samples are presented in Figure 1 to 3 and Table 1, which shows the addition of 5:3 vol.\% $\mathrm{SiC}$ and $\mathrm{TiO}_{2}$ respectively,represented as sample D. Figure 4 shows the SEM/EDS data of the samples sintered at the various temperatures.

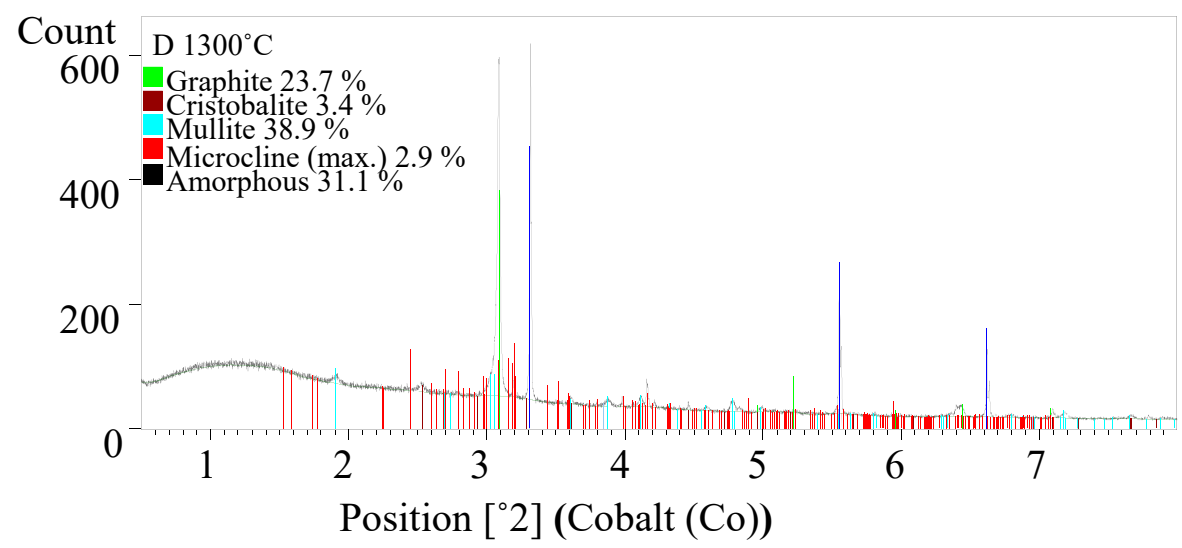

Figure 1. X-Ray Diffractometry Pattern of Sample D at $1300^{\circ} \mathrm{C}$

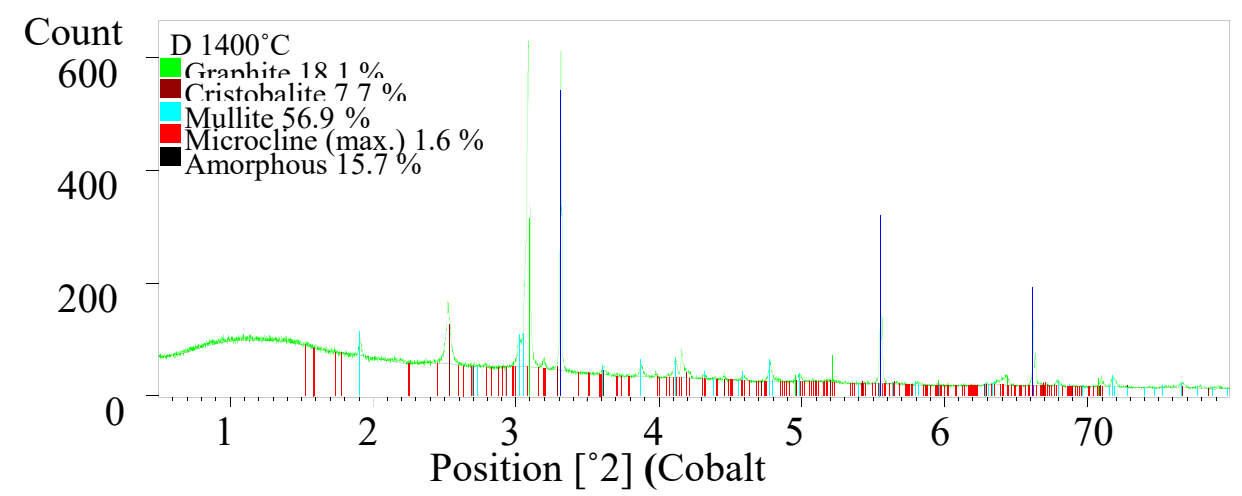

Figure 2. X-Ray Diffractometry Pattern of Sample D at $1400^{\circ} \mathrm{C}$

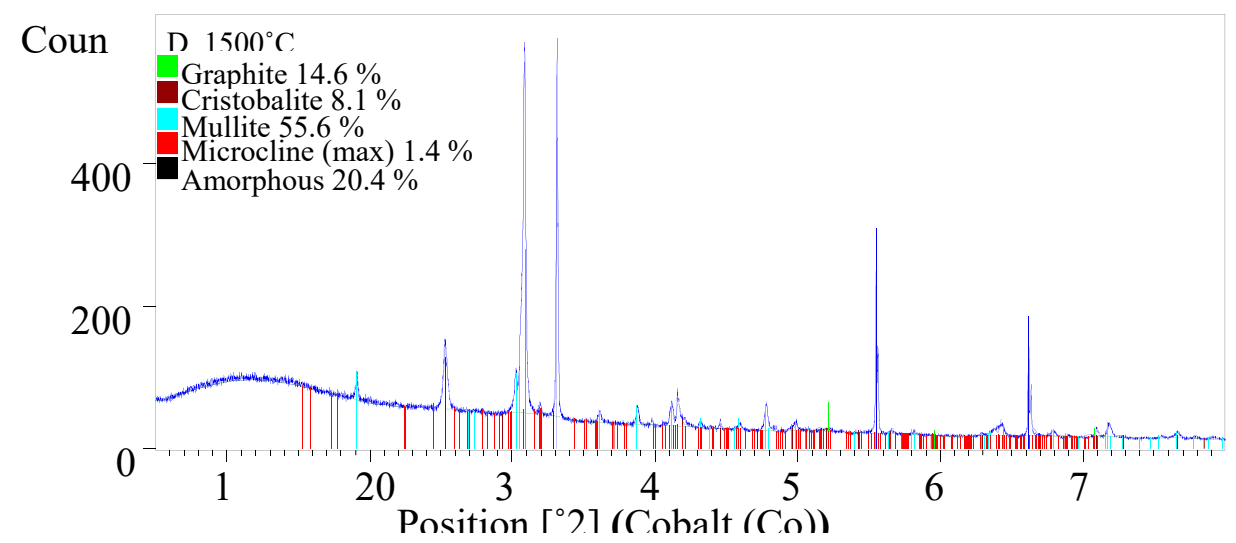

Figure 3. X-Ray Diffractometry Pattern of Sample D at $1500^{\circ} \mathrm{C}$ 
Table 1. XRD Result of Sintered Sample D Ceramic Composite showing the quantity of different phases present.

\begin{tabular}{|l|l|l|l|l|l|}
\hline sintered D & \multicolumn{5}{|c|}{ Mineralogica/Phase constituent (wt.\%) } \\
\hline Temp. $\left({ }^{\circ} \mathrm{C}\right)$ & Graphite & Cristobalite & Mullite & Microcline & Amorphous \\
\hline 1300 & 23.7 & 3.42 & 38.88 & 2.94 & 31.06 \\
\hline 1400 & 18.14 & 7.67 & 56.86 & 1.62 & 15.71 \\
\hline 1500 & 14.56 & 8.07 & 55.57 & 1.36 & 20.44 \\
\hline
\end{tabular}

From the Table 1, the effects of sintering temperature on the phase development in the sintered ceramic composite samples to which 5 vol. $\% \mathrm{SiC}$ and 3 vol. $\% \mathrm{TiO}_{2}$ have been added are clearly depicted. From the results obtained from XRD analysis, the sintered sample contains mullite, graphite, amorphous, cristobalite (silica) and microcline phases. It is observed that with an increase in sintering temperature, the mullite phase increased rapidly from $38.88 \%$ at $1300^{\circ} \mathrm{C}$ to $56.86 \%$ at $1400^{\circ} \mathrm{C}$. It then reduced slightly to $55.57 \%$ when sintered at $1500^{\circ} \mathrm{C}$. Similarly, the cristobalite phase is observed to increase from $3.42 \%$ at $1300^{\circ} \mathrm{C}$ to $7.67 \%$ as the sintering temperature increased to $1400^{\circ} \mathrm{C}$. Further increase in the sintering temperature to $1500^{\circ} \mathrm{C}$ resulted into cristobalite phase increasing to $8.07 \%$. This is because the kaolinite content of the kaolin undergoes mullitization process as discussed by Aramide et al., (2016) [16].

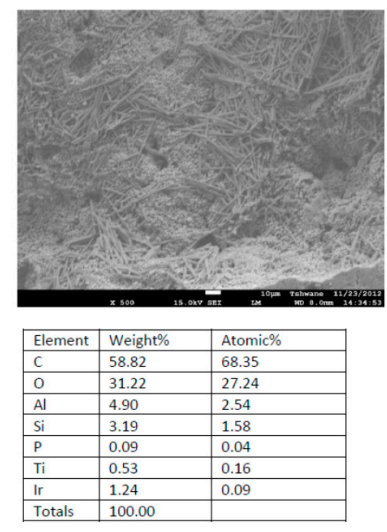

(a)

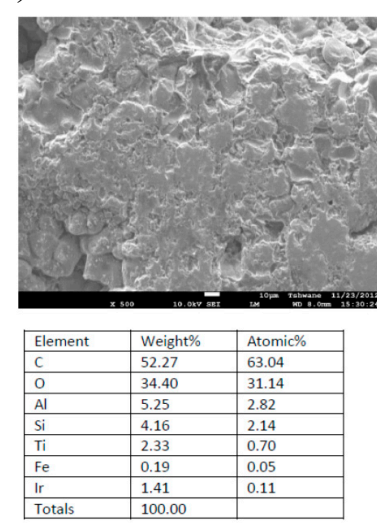

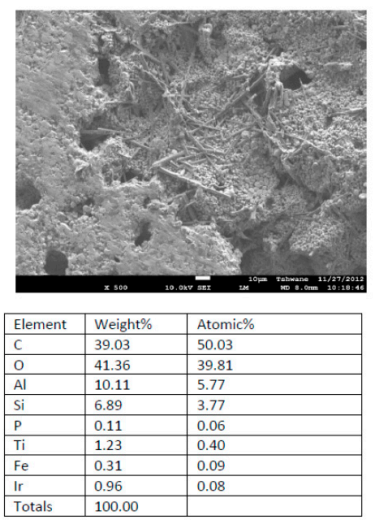
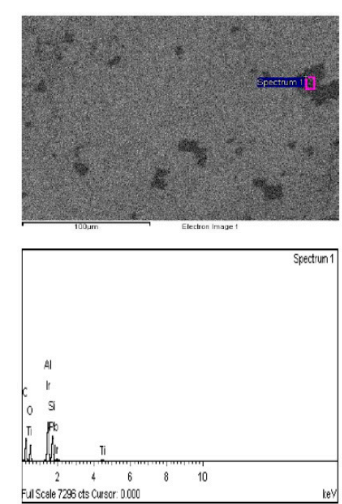

(b)
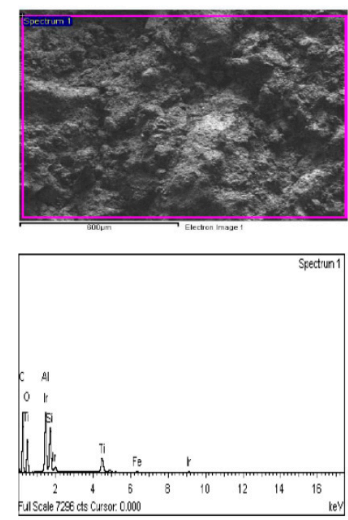

(c)

Figure 4. SEM/EDS data of the various samples; (a) Sample D sintered at $1300^{\circ} \mathrm{C}$, (b) Sample D sintered at $1400^{\circ} \mathrm{C}$ and (c) Sample D sintered at $1500^{\circ} \mathrm{C}$ 
In the mullitization process, the kaolinite is transformed into mullite and excess silica; this explains the origin of the cristobalite. As observed from the table, the amount of the mullite and cristobalite formed increased generally with the sintering temperature. Moreover the presence of the titania as an additive in the sample aids the mullitization process. The mullite fibres could be be seen in the SEM images of the samples in Figure 4.

Furthermore, the graphite phase is observed to reduce from $23.7 \%$ at $1300^{\circ} \mathrm{C}$ to $18.14 \%$ at $1400^{\circ} \mathrm{C}$ and then to $14.56 \%$ as the sintering temperature is increased to $1500^{\circ} \mathrm{C}$. Similarly, microcline is also observed to reduce from $2.94 \%$ at $1300^{\circ} \mathrm{C}$ to $1.62 \%$ as the sintering temperature is increased to $1400^{\circ} \mathrm{C}$. It further reduced to $1.36 \%$ as the sintering temperature is increased to $1500^{\circ} \mathrm{C}$. In the case of the microcline (a feldspar mineral) it aids the liquid phase sintering of the ceramic which produce secondary mullite fibers within the ceramic matrix ${ }^{11}$. The explanation for the reduction in the amount of graphite as the sintering temperature increased from $1300^{\circ} \mathrm{C}$ to $1500^{\circ} \mathrm{C}$ is that the amounts are measured in percentages, relative to other constituents, once the amounts of cristobalite and mullite increased with increased sintering temperature, it is expected that some other constituents will reduce. Amorphous phase reduced from $1300^{\circ} \mathrm{C}$ to $1400^{\circ} \mathrm{C}$ and increased slightly from $1400^{\circ} \mathrm{C}$ when sintered at $1500^{\circ} \mathrm{C}$. Generally, the amorphous content in these sample are more than what was earlier reported [16] for the same sample without any additive.

\subsubsection{Effects of Sintering Temperature on the Physical and Mechanical Properties of the Mullite-Carbon Ceramic Composite Samples}

Evaluation of effects of adding 5:3 vol. \% $\mathrm{SiC} / \mathrm{TiO}_{2}$ respectively on various physical and mechanical properties of mullite-carbon ceramic composite samples sintered at varied sintering temperature. Below are the results of various physical and mechanical properties of sample D.

\subsubsection{Apparent Porosity}

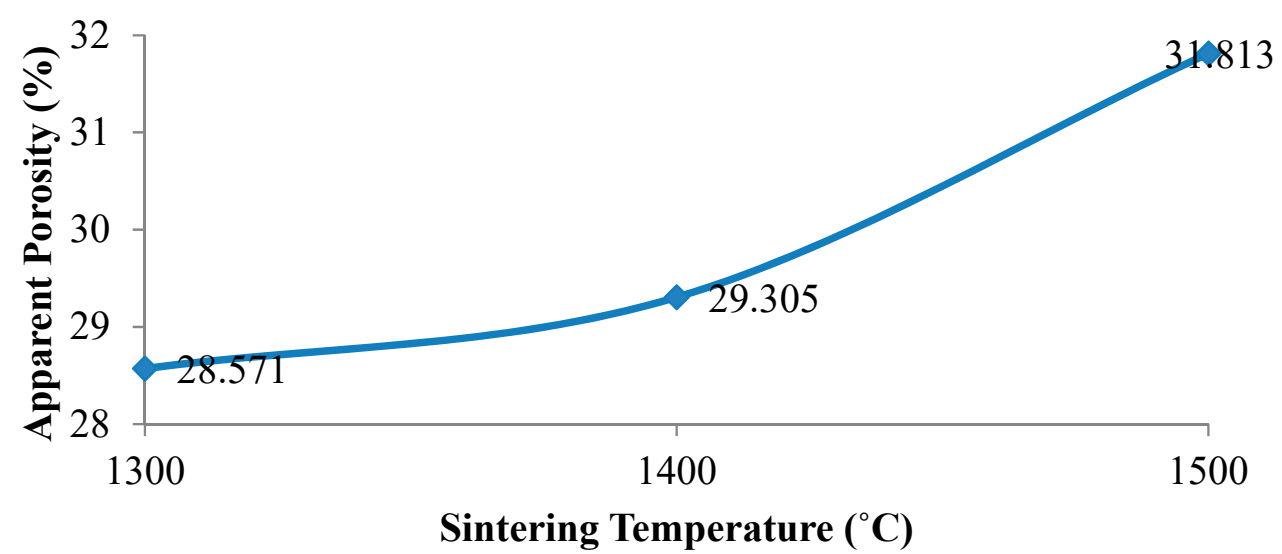

Figure 5. Effects sintering temperature on the apparent porosity of the ceramic sample

The effect of sintering temperature on the apparent porosity of the ceramic samples is clearly shown in Figure 5 and Table 2. From the Figure, it is observed that the apparent porosity of the sample at $1300^{\circ} \mathrm{C}$ is $28.571 \%$, as the sintering temperature increase to $1400^{\circ} \mathrm{C}$ the apparent porosity slightly increased to $29.305 \%$ further increase in the sintering temperature to $1500^{\circ} \mathrm{C}$ leads to an increase in the apparent porosity of the sample to $31.813 \%$. This could be because of the 
reduction in the amount of graphite contents of the samples as the sintering temperature is increased. The oxidation of some of the graphite in the ceramic sample will leave pores within the matrix of the sample. This could account for the increased porosity as the sintering temperature increased. This implies that the densification reduced with increase in sintering temperature. Some researchers [21-23] have reported that high temperature oxidations of graphite lead to drastic deterioration due to graphite diminution, which result to pores in the samples.

\subsubsection{Bulk Density}

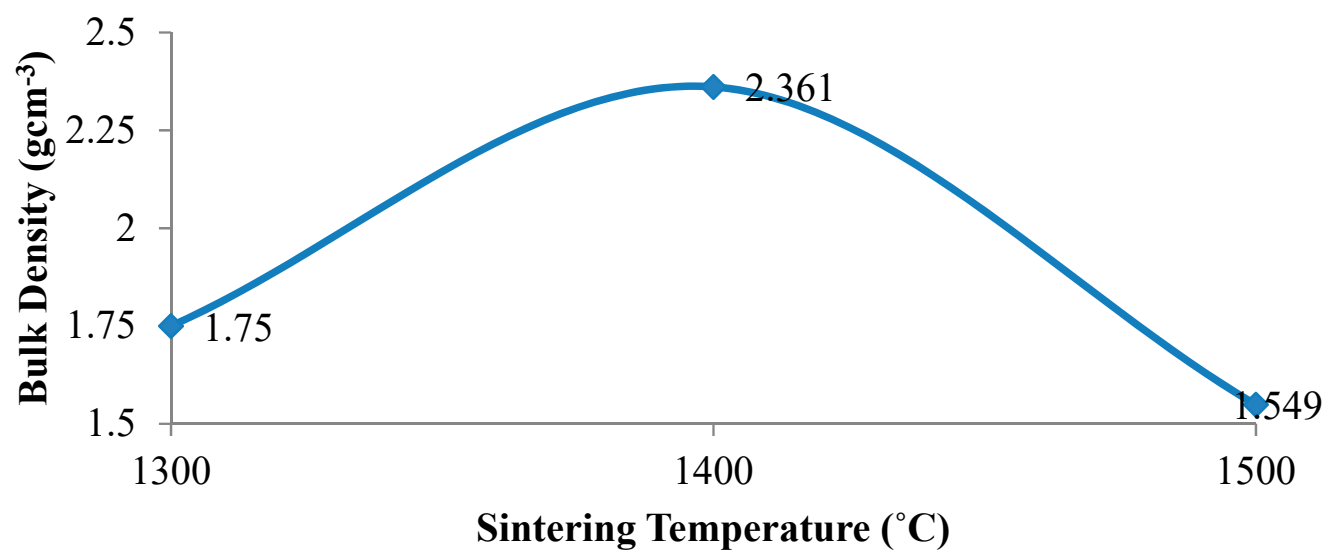

Figure 6. Effects of sintering temperature on the bulk density of the ceramic sample

The effect of sintering temperature on the bulk density at varied sintering temperature is clearly depicted in Figure 6 and Table 2. From the Figure, it is observed that the bulk density the ceramic sample at $1300^{\circ} \mathrm{C}$ is $1.75 \mathrm{gcm}^{-3}$ as the sintering temperature increased to $1400^{\circ} \mathrm{C}$ the bulk density increased to its maximum of $2.361 \mathrm{gcm}^{-3}$, further increase in the sintering temperature to $1500^{\circ} \mathrm{C}$, the bulk density then reduced to $1.549 \mathrm{gcm}^{-3}$. It could be stated that the sample attained its maximum densification at $1400^{\circ} \mathrm{C}$. Comparing the above with the results obtained for the samples without any additive [16], it is observed that the bulk densities of the samples were improved upon.

\subsubsection{Cold Crushing Strength}




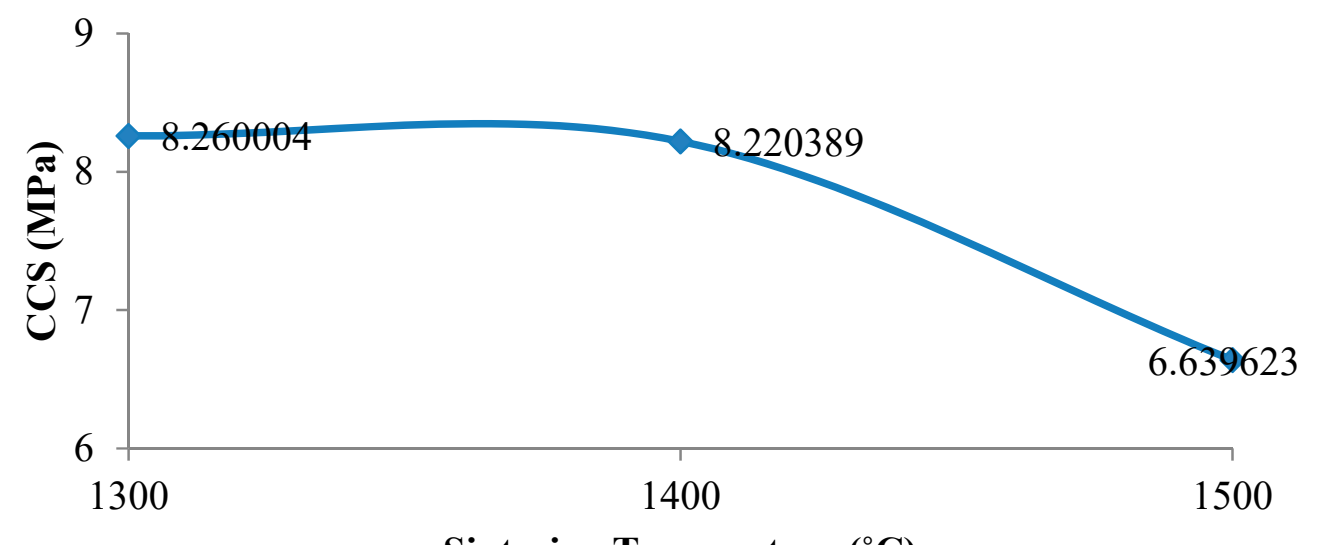

Figure 7. Effects of sintering temperature on the cold crushing strength of the ceramic sample

The effect of sintering temperature on the cold crushing strength of the sintered ceramic samples is shown in Figure 7 and Table 2. From the Figure, it is observed that the cold crushing strength of sample at $1300^{\circ} \mathrm{C}$ is $8.26 \mathrm{Mpa}, 8.22 \mathrm{Mpa}$ at $1400^{\circ} \mathrm{C}$ and $6.64 \mathrm{Mpa}$ at $1500^{\circ} \mathrm{C}$. This implies that with an increase in the sintering temperature, the cold crushing strength slightly reduced from $1300^{\circ} \mathrm{C}$ to $1500^{\circ} \mathrm{C}$. The results correspond to apparent porosity of the sample. The reason for this is that the higher the bulk density of the sample, the higher the load bearing capacity of the sample $[2,24]$. It can also be observed cold crushing strength of the samples with $\mathrm{SiC} / \mathrm{TiO}_{2}$, is higher than those without any additive [16].

\subsubsection{Modulus of Elasticity}

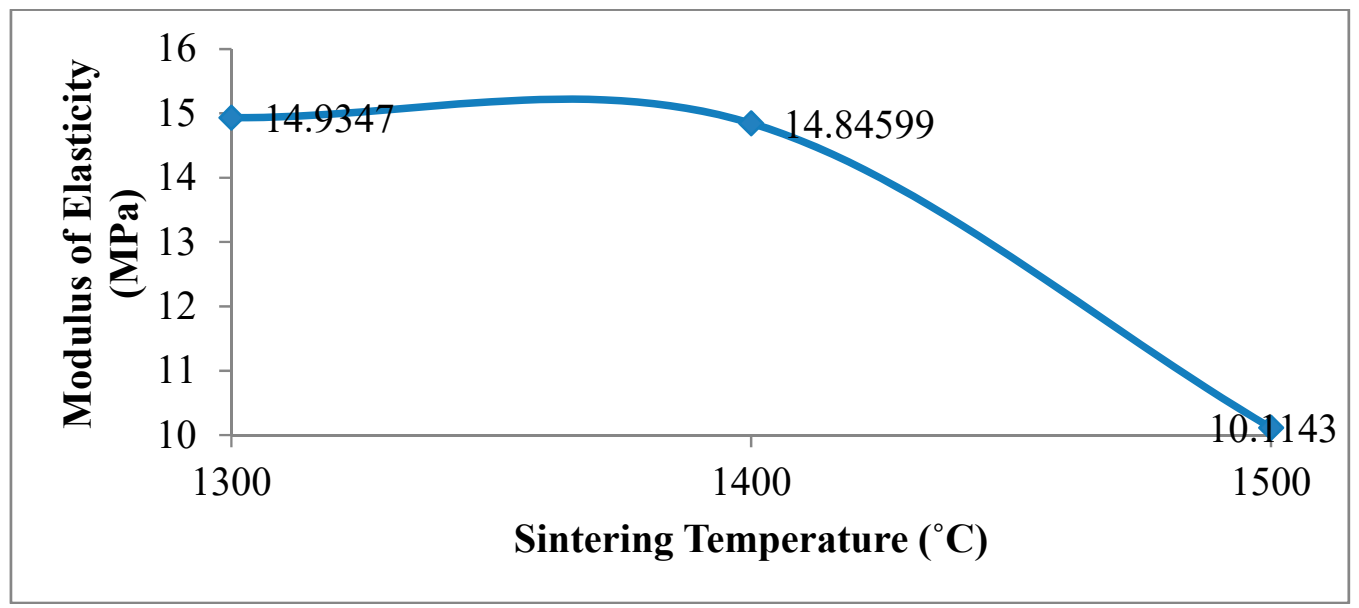

Figure 8. Effects of sintering temperature on the Modulus of Elasticityof the ceramic sample

The effect of sintering temperature on the modulus of elasticity (MOE) of the sintered samples is shown in Figure 8 and Table 2. From the Figure, it is observed that the elastic modulus of the sample at $1300^{\circ} \mathrm{C}$ is $14.935 \mathrm{Mpa}, 14.846 \mathrm{Mpa}$ at $1400^{\circ} \mathrm{C}$ and $10.114 \mathrm{Mpa}$ at $1500^{\circ} \mathrm{C}$. This implies 
that with an increase in sintering temperature, the modulus of elasticity reduced from $1300^{\circ} \mathrm{C}$ to $1500^{\circ} \mathrm{C}$ as dictated by the CCS Of the samples. The results correspond to apparent porosity dictation of the sample. The reason for this is that the higher the bulk density of the sample, means that the sample contains more matter to bear the applied load $[2,24]$.

\subsubsection{Absorbed Energy}

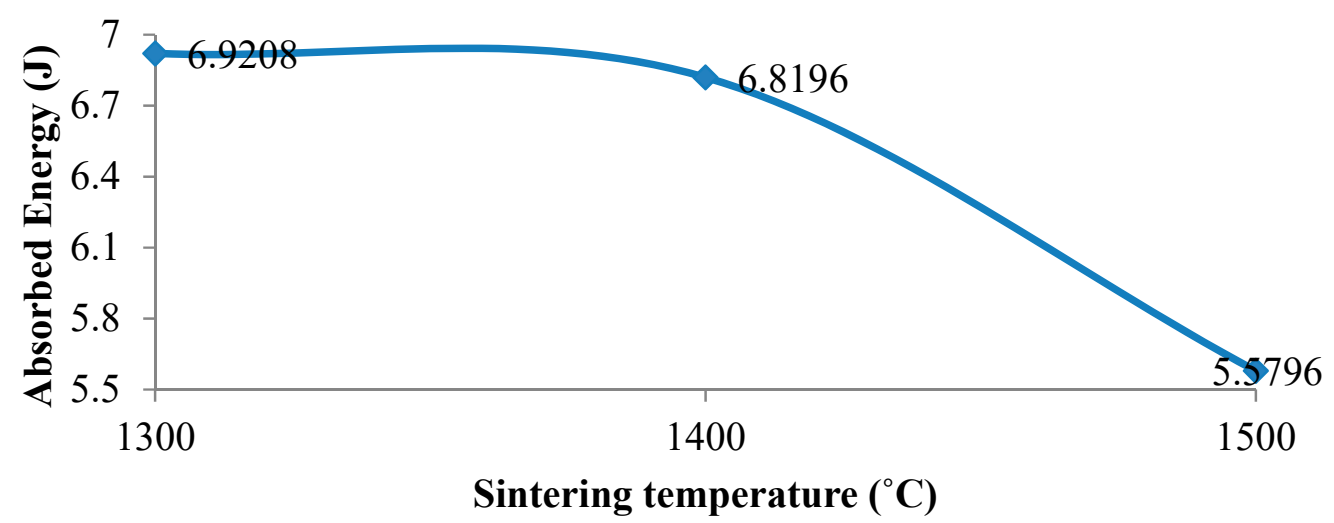

Figure 9. Effects of sintering temperature on the Absorbed Energy of the ceramic sample

The effect of sintering temperature on the absorbed energy of the sintered samples is clearly shown in Figure 9 and Table 2. From the Figure, it is observed that the absorbed energy of sample $\mathrm{D}$ at $1300^{\circ} \mathrm{C}$ is $6.92 \mathrm{~J}, 6.82 \mathrm{~J}$ at $1400^{\circ} \mathrm{C}$ and $5.58 \mathrm{~J}$ at $1500^{\circ} \mathrm{C}$. This implies that with an increase in sintering temperature, the absorbed energy reduced from $1300^{\circ} \mathrm{C}$ to $1500^{\circ} \mathrm{C}$. In this case, the samples followed the CCS variation trend. The results correspond to apparent porosity dictation of the sample. The reason for this is that the higher the bulk density of the sample means that the sample contains more matter to bear the applied load [2,24].

\subsubsection{Linear Expansion}

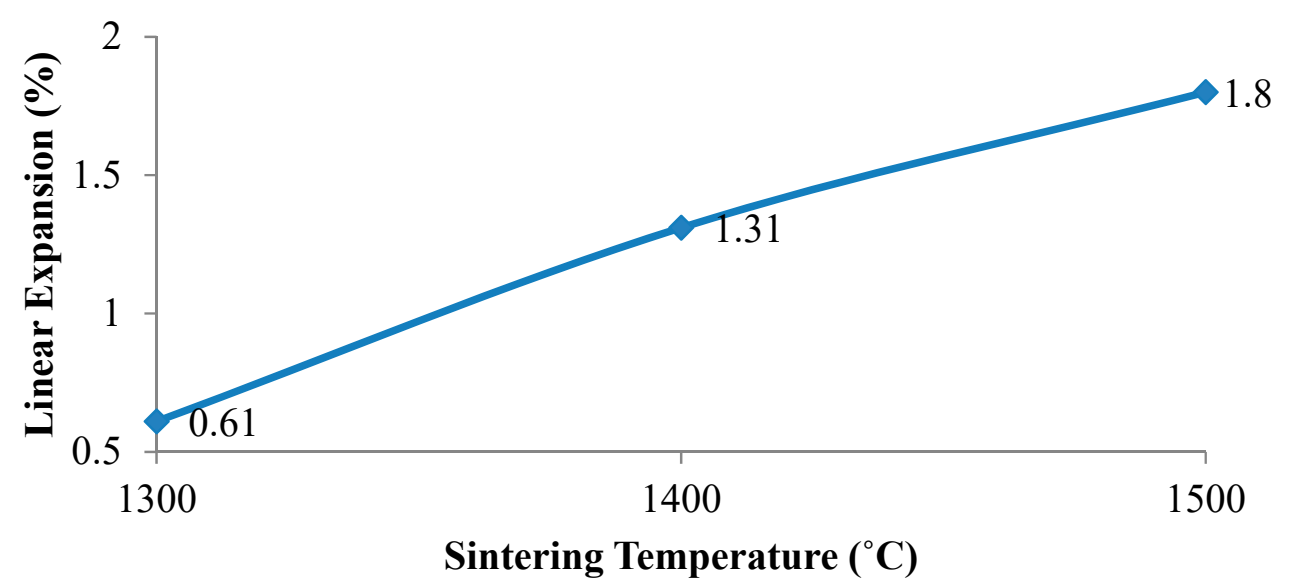

Figure 10. Effects of Sintering Temperature on the Linear Expansionof Sample D. 
The effect of adding (5:3) vol. \% $\mathrm{SiC} / \mathrm{TiO}_{2}$ respectively on the linear expansion of the sintered samples is clearly shown in Figure 10 and Table 2. From the Figure, it is observed that the linear expansion of sample $\mathrm{D}$ is $0.61 \%$ at $1300^{\circ} \mathrm{C}, 1.31 \%$ at $1400^{\circ} \mathrm{C}$ and $1.8 \%$ at $1500^{\circ} \mathrm{C}$. The linear expansion of sample D increased significantly from $1300^{\circ} \mathrm{C}$ to $1500^{\circ} \mathrm{C}$. This implies that an increase in sintering temperature aids the linear expansion of the samples this might be trace to the graphite in the samples. The limited expansion recorded makes the composite to be suitable for high temperature applications. A refractory material should be able to maintain sufficient dimensional stability at high temperatures and after/during repeated thermal cycling [25].

\subsubsection{Volumetric Shrinkage}

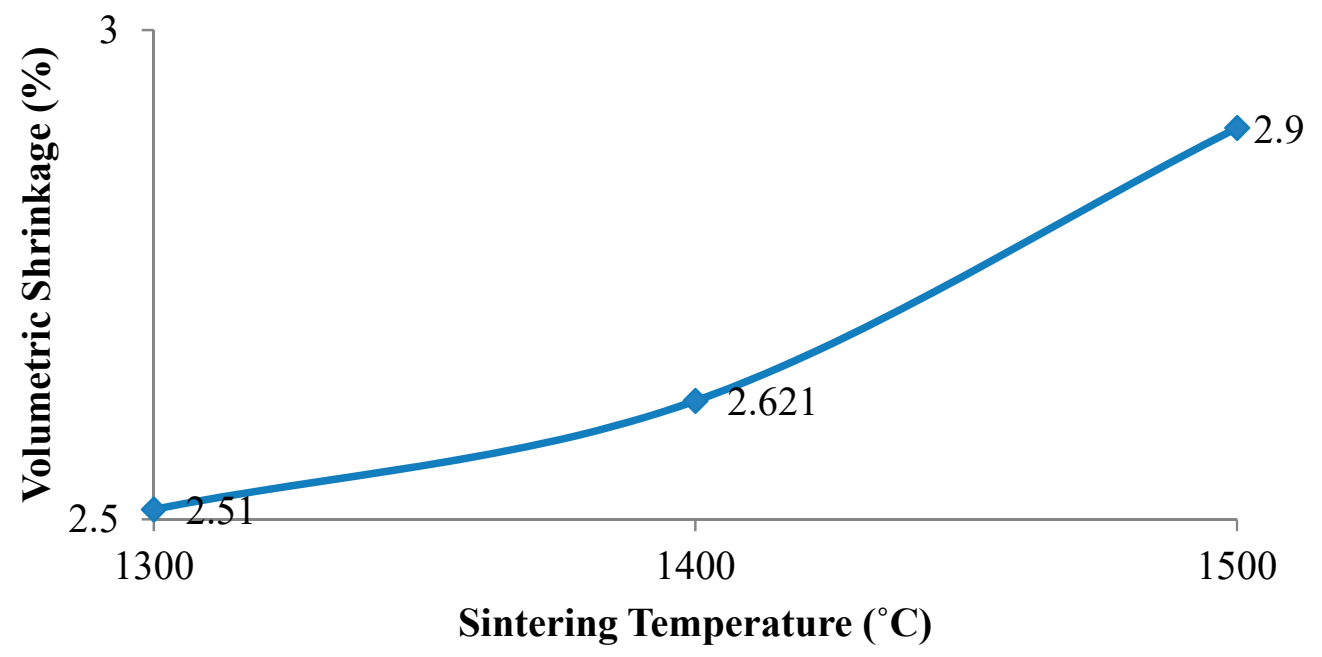

Figure 11. Effects of Sintering Temperature on the Volumetric Shrinkageof Sample D.

The effect of adding (5:3) vol. \% $\mathrm{SiC} / \mathrm{TiO}_{2}$ respectively on the volumetric shrinkage of the sintered samples is clearly shown in Figure 11 and Table 2. From the Figure, it is observed that the volumetric shrinkage of sample $\mathrm{D}$ is $2.51 \%$ at $1300^{\circ} \mathrm{C}, 2.62 \%$ at $1400^{\circ} \mathrm{C}$ and $2.9 \%$ at $1500^{\circ} \mathrm{C}$. This implies that the volumetric shrinkage of sample $\mathrm{D}$ increased slightly from $1300^{\circ} \mathrm{C}$ to $1500^{\circ} \mathrm{C}$. This is as achieved for the sample's linear expansion. The limited expansion recorded makes the composite to be suitable for high temperature applications. The volumetric shrinkage of the samples recorded here is smaller than those reported by Aramide et al [16], for the samples without any additive.

\subsubsection{Oxidation Resistance}



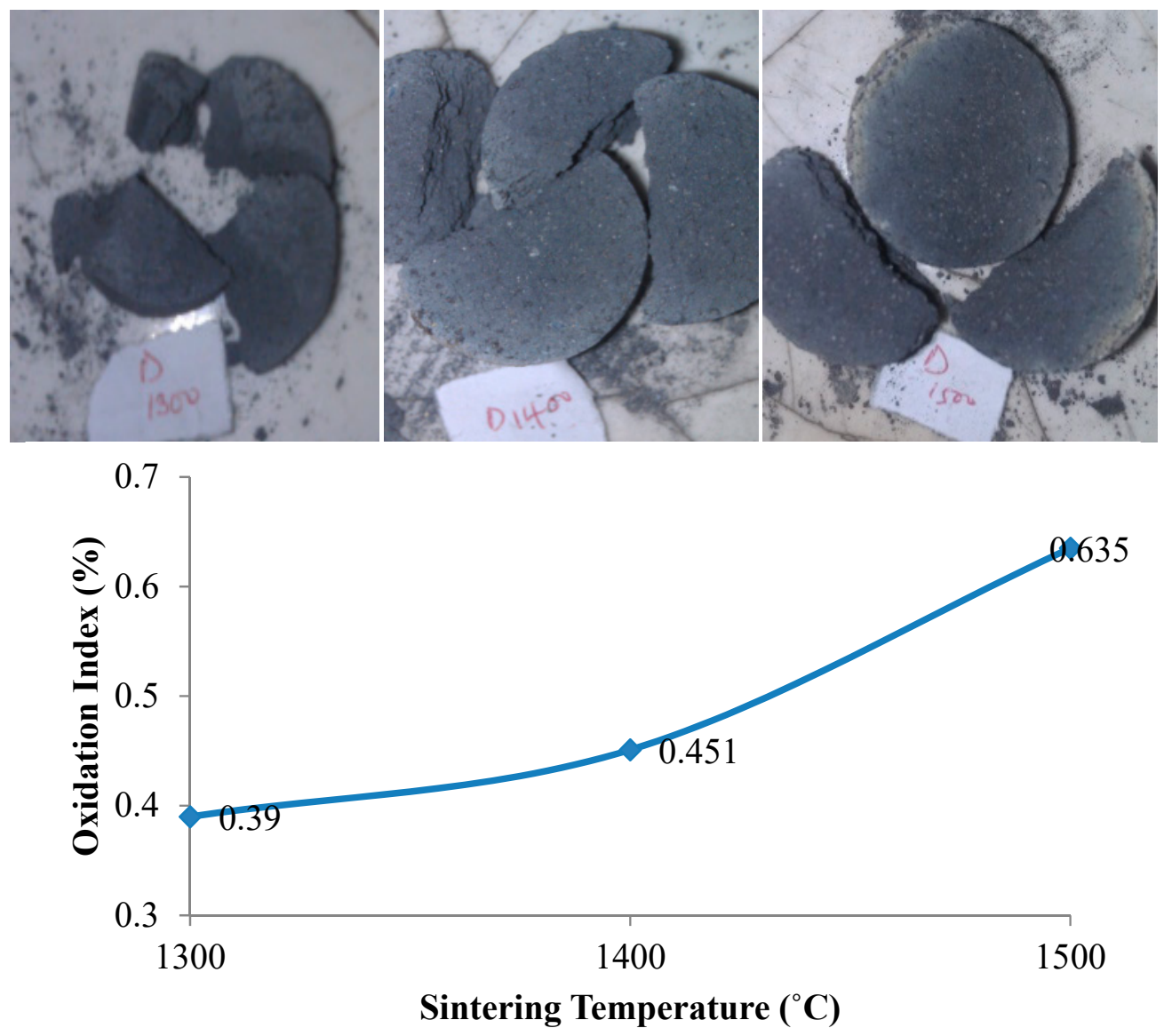

Figure 12. Effects of Sintering Temperature on the Oxidation Resistanceof Sample D.

The effect of adding (5:3) vol. \% $\mathrm{SiC} / \mathrm{TiO}_{2}$ respectively on the oxidation resistance of the sintered samples is clearly shown in Figure 12 and Table 2. From the Figure, it is observed that the oxidation index of sample D at $1300^{\circ} \mathrm{C}$ is $0.39 \%, 0.451 \%$ at $1400^{\circ} \mathrm{Cand} 0.635 \%$ at $1500^{\circ} \mathrm{C}$. The oxidation index of sample D increased with an increase in sintering temperature from $1300^{\circ} \mathrm{C}$ to $1500^{\circ} \mathrm{C}$. A clear indication that the oxidation resistance reduced as the sintering temerature was increased on adding $\mathrm{SiC} / \mathrm{TiO}_{2}$. The $\mathrm{SiC}$ present inhibit oxidation of graphite by reacting with the Oxygen present to form $\mathrm{SiO}_{2}$ that coat the samples from further oxidation of graphite. According to Roy et al. (2014) [26] SiC oxidation in most cases is passive with wide variation in the reaction rates and the morphology of the reaction products. During passive oxidation, $\mathrm{SiO}_{2}$ liberated forms a dense layer on the surface of $\mathrm{SiC}$ which acts as an anti-oxidation protective layer [27]. Studies showed that the layers formed on the composite surfaces acts as physical protection barriers for oxygen penetration. Tripp et al., [28] and Ronald, [29] has reported that reactions where silica is formed are more desirable for protection against oxidation. Comparing this with the oxidation indices of samples without additives as reported by Aramide et al [16], it can be observed that the oxidation indices of the samples with $\mathrm{SiC} / \mathrm{TiO}_{2}$ additives are lower than those without any additive. It can be infered that the additves improved on the oxidation resistance of the samples.

Table 2. Summarize the physical and mechanical properties sintered Sample D ceramic composite produced. 


\begin{tabular}{|c|c|c|c|c|c|c|c|c|}
\hline Sample D & \multicolumn{8}{|c|}{ Physical and Mechanical Properties of the ceramic composite } \\
\hline $\begin{array}{l}\text { Temp. } \\
\left({ }^{\circ} \mathrm{C}\right)\end{array}$ & $\begin{array}{l}\text { Cold } \\
\text { crushing } \\
\text { strength } \\
\text { (Mpa) }\end{array}$ & $\begin{array}{l}\text { Modulus } \\
\text { of } \\
\text { Elasticity } \\
\text { (Mpa) }\end{array}$ & $\begin{array}{l}\text { Absorb } \\
\text { ed } \\
\text { Energy } \\
(\%)\end{array}$ & $\begin{array}{l}\text { Apparen } \\
\mathrm{t} \\
\text { Porosity } \\
(\%)\end{array}$ & $\begin{array}{l}\text { Bulk } \\
\text { Density } \\
\left(\mathrm{g} / \mathrm{cm}^{3}\right)\end{array}$ & $\begin{array}{l}\text { Oxidati } \\
\text { on } \\
\text { Index } \\
(\%)\end{array}$ & $\begin{array}{l}\text { Linear } \\
\text { Expansi } \\
\text { on }(\%)\end{array}$ & $\begin{array}{l}\text { Volume } \\
\text { tric } \\
\text { Shrinka } \\
\text { ge }(\%)\end{array}$ \\
\hline 1300 & 8.26000 & 14.93470 & 6.8196 & 28.571 & 1.750 & 0.39 & 0 & 2.510 \\
\hline 1400 & 8.22039 & 14.84599 & 6.9208 & 29.305 & 2.361 & 0.45 & 1. & 2.621 \\
\hline 1500 & 6.63962 & 10.11430 & 5.5796 & 31.813 & 1.549 & 0.635 & 1.800 & 2.900 \\
\hline
\end{tabular}

Summarily, According to Chester ${ }^{31}, 5 \mathrm{MPa}$ was recommended as the minimum CCS value for refractory clay materials and the acceptable porosity level of refractory is within $10-30 \%$. This implies that the mullite-carbon ceramic composite developed is suitable for use for high temperature application.

\section{Conclusion}

From the data discussed above it is concluded that;

The addition of $\mathrm{SiC} / \mathrm{TiO}_{2}$ additives to the samples made them to possess very low oxidation indices when compared with sample with no additive. This also resulted in improvement in the bulk densities and cold crushing strength of the sample when compared with those without additives. The addition of $\mathrm{SiC} / \mathrm{TiO}_{2}$ additives improves on the high temperature oxidation resistance of the sample

\section{Acknowledgements}

The financial assistance of The World Academy of Science (TWAS) in collaboration with National Research Foundation (NRF) towards this research is hereby acknowledged. Opinions expressed and conclusions arrived at, are those of the author and are not necessarily to be attributed to TWAS and NRF

\section{Reference}

[1] Aramide F.O., Alaneme K.K., Olubambi P.A., Borode J.O., In-Situ synthesis of mullite fibers reinforced Zircon-Zirconia refractory ceramic composite from clay based materials, Int. J. of Mater. and Chem., 2015, 5(6), 127-139.

[2] Aramide F.O and Seidu S.O. Production of refractory lining for diesel fired rotary furnace from locally sourced kaolin and potter's clay, J. of Min. and Mater. Character. and Eng., 2013, 1, 75 79.

[3] Callister W.D., Materials science and engineering: an introduction, 7th ed. John Wiley \& Sons, Inc, 2007.

[4] Dag L and Annette M., Advanced Materials and Structures and their Fabrication Processes, Narvik University College, HiN, 2007, 55, 61

[5] Low I.M., Skala R.D., Perera D.S., Fracture properties of layered mullite/zirconia-toughened alumina composites, J. of Mater. Sc. Lett., 1994, 13, 1334-1336.

[6] Das K and Banerjee G. Mechanical properties and microstructures of reaction sintered mullite-zirconia composites in the presence of an additive - dysprosia, J. of Eu. Ceram. Soc., 2000, 20 (2), 153 - 157. 
[7] Rendtorff N.M., Garrido L.B. and Aglietti E.F., Thermal shock behavior of dense mullitezirconia composites obtained by two processing routes, Ceram. Int., 2008, 34(8), 2017 - 2024.

[8] Ozturk C, and Tur Y.K., Processing and mechanical properties of textured mullite/zirconia composites, J. Eu. Ceram. Soc., 2007, 27 (2-3), 1463-1467.

[9] Badiee H, Ebadzadeh T and Golestani-Fard F., The effect of additives on mullitization of Iranian andalusite, 44th International Colloquium on Refractories, Achen, 2001, 126-130.

[10] Ebadzadeh T., Ghasemi E., Effect of $\mathrm{TiO}_{2}$ addition on the stability of $\mathrm{t}-\mathrm{ZrO}_{2}$ in mullite $\mathrm{ZrO}_{2}$ composites prepared from various starting materials, Ceram. Int., 2002, 28, 447-450.

[11] Aramide F.O., Alaneme K.K., Olubambi P.A. and Borode J.O., Effects of 0.2Y-9.8ZrO 2 addition on the mechanical properties and phase development of sintered ceramic produced from Ipetumodu clay, Faculty Engineering Hunedoara-Int. J. of Eng., 2014; 7(4), 343 - 352.

[12] Chandra D, Das G.C., Sengupta U. and Maitra S., Studies on the reaction sintered zirconiamullite-alumina composites with titania as additive, Cerâmica, 2013, 59, 487 - 494.

[13] Aksel C and Komicezny F., Mechanical properties and thermal shock behaviour of PSR333 alumina-mullite-zirconia refractory materials, Glass Int., 2001, 1, 16 - 18.

[14] Kausik, D; Sukhen, D. and Swapan, K. D. Effect of substitution of fly ash for quartz in Triaxial kaolin-quartz-feldspar system, J. Eur. Ceram. Soc., 2004, 24, 3169-3175.

[15] Omani, H; Hamidouche, M; Madjoubi, M.A; Louci, K; Bouaouadja, N. and Etude, de la Transformation de trois nuances de kaolin en fonction de la temperature, Silicate Industriel, 2000, 65(11-12), 119-124.

[16] Aramide F.O., Akintunde I.B., Oyetunji A., Insitu synthesis and characterization of mullitecarbon refractory ceramic composite from Okpella kaolin and graphite, Usak University J. of Mater. Sc., 2016, 25-42

[17] Nabil R.B., Barbara Z., Sample preparation for atomic spectrometric analysis: An overview, Adv. in Appl. Sc. Res., 2012, 3 (3), p. 1733-1737

[18] Aramide F. O., Effects of sintering temperature on the phase developments and Mechanical properties ifon clay, Leonardo J. of Sc., 2015, 26, 67-82.

[19] Kuldeep, Singh, Specially Treated Graphite Fortified Alumina-Silicon Carbide- Carbon Refractories: Fabrication and Properties, Master of Technology Thesis Department of Ceramic Engineering National Institute of technology Rourkela, 2014, 17-40.

[20] Subham, M., Expanded graphite fortified magnesia-carbon refractories: fabrication and properties, Master of Technology Thesis Department of Ceramic Engineering National Institute of technology Rourkela, 2013, 11-24.

[21] Sadrnezhaad S.K. Nemati Z.A, Mahshid S, Hosseini S and Hashemi B., Effect of Al antioxidant on the rate of oxidation of carbon in MgO-C Refractory, J. of Am. Ceram. Soc., 2007, 90 (2), $509-515$.

[22] Sadrnezhaad SK, Mahshid S, Hashemi B and Nemati ZA., Oxidation Mechanism of C In MgO-C Refractory Bricks, J. of Am. Ceram. Soc., 2006, 89(4), 1308 - 1316.

[23] Nemati Z, Sadrnezhaad S and Mooghari HRA., Effect of ferrosilicon, silicon and aluminum antioxidants on microstructure and mechanical properties of magnesia-graphite refractory, Refra. Appl. \& News, 2005, 10(6), 17-23.

[24] Aramide F.O., Production and characterization of porous insulating fired bricks from ifon clay with varied sawdust admixture, J. of Min. and Mater. Charact. and Eng., 2012, 11, 970 - 975.

[25] Gupta O.P., Element of fuels, furnaces and refractories, Romesh Chander Khanna Publishers Delhi India Fifth edition, 2010. 
[26] Roy J., Chandra S., Das S., Maitra S., Oxidation behaviour of silicon carbide - A review, Rev. Adv. Mater. Sci., 2014, 38, 29-39.

[27] Auweter-Kurtz M., Hilfer G., Habiger H., Yamawaki K., Yoshinaka T., Speckmann H.D., Investigation of oxidation protected $\mathrm{C} / \mathrm{C}$ heat shield material in different plasma wind tunnels, Acta Astronau., 1999, 45, 93.

[28] Tripp W.C., Davis H.H., Graham H.C., Effects of SiC additions on the oxidation of $\mathrm{ZrB}_{2}$, Ceram. Bull., 1973, 52 (8), 612-616.

[29] Ronald A. McCauley, Corrosion of Ceramic and Composite Materials, Marcel Dekker Inc, New York, 2004, 54, 104.

[30] Chester, J.H., Refractories, Production and Properties, The Iron And Steel Institute, London, UK., 1973. 